Published online 2017 April 13.

Abstract

\title{
Ultrasound Guided Interventions (25 min)
}

\section{Kambiz Motamedi ${ }^{1, *}$}

${ }^{1}$ Professor of Radiology, David Geffen School of Medicine, University of California, Los Angeles, USA

"Corresponding author: Kambiz Motamedi, MD, University of California, Director, UCLA Beach Imaging and Interventional Center USA, Los Angeles. E-mail: KMotamedi@mednet.ucla.edu

Received 2016 December 21; Accepted 2017 February 08.

\section{Abstract}

Key features covered by this talk are, choice of transducers and needles; patient positioning; joint injections and aspirations; tendon sheath injections; cyst aspirations; Biopsies.

This is an abstract presented in the 33rd Iranian congress of radiology (ICR) and the 15th congress of Iranian radiographic science association (IRSA). 